\title{
High expression of gabarap/l is associated with a better outcome for patients with lymph node-positive breast cancer
}

\author{
A Berthier ${ }^{1,6}$, S Seguin 1,6, AJ Sasco², JY Bobin ${ }^{3}$, G De Laroche ${ }^{4}$, J Datchary5 ${ }^{5}$ S Saez ${ }^{3}$, C Rodriguez-Lafrasse ${ }^{3}$, \\ F Tolle', A Fraichard', M Boyer-Guittaut', M Jouvenot', R Delage-Mourroux' and F Descotes*,3 \\ 'Université de Franche-Comté, UFR Sciences et Techniques, IFR 133, Besançon EA3922, France; 'Epidemiology for Cancer prevention, Inserm U 897 \\ Université Victor Segalen Bordeaux 2, Bordeaux, France; ${ }^{3}$ Centre Hospitalier Lyon Sud, Hospices Civils de Lyon, Pierre Bénite, France; ${ }^{4}$ Clinique Mutualiste, \\ St Etienne, France; ${ }^{5}$ Centre Hospitalier Régional, Annecy, France
}

BACKGROUND: This study evaluates the relation of the early oestrogen-regulated gene gabarap/I to cellular growth and its prognostic significance in breast adenocarcinoma.

METHODS: First, the relation between GABARAPLI expression and MCF-7 growth rate was analysed. Thereafter, by performing macroarray and reverse transcriptase quantitative-polymerase chain reaction (RT-qPCR) experiments, gabarap/l expression was quantified in several histological breast tumour types and in a retrospective cohort of 265 breast cancers.

RESULTS: GABARAPLI overexpression inhibited MCF-7 growth rate and gabarap// expression was downregulated in breast tumours. Gabarap/I mRNA levels were found to be significantly lower in tumours presenting a high histological grade, with a lymph nodepositive $(\mathrm{pN}+)$ and oestrogen and/or progesterone receptor-negative status. In univariate analysis, high gabarap/l levels were associated with a lower risk of metastasis in all patients (hazard ratio (HR) 4.96), as well as in pN+patients (HR I4.96). In multivariate analysis, gabarap/l expression remained significant in all patients (HR 3.63), as well as in pN+ patients (HR 5.65). In univariate or multivariate analysis, gabarap/l expression did not disclose any difference in metastasis risk in lymph node-negative patients.

CONCLUSIONS: Our data show for the first time that the level of gabarap/I mRNA expression in breast tumours is a good indicator of the risk of recurrence, specifically in $\mathrm{pN}+$ patients.

British Journal of Cancer (2010) 102, 1024-1031. doi:I0.1038/sj.bjc.6605568 www.bjcancer.com

Published online 2 March 2010

(c) 2010 Cancer Research UK

Keywords: breast cancer; gabarap/l; prognosis; lymph node positive

Breast cancer is the most frequently diagnosed cancer among women worldwide, with more than 1.3 million cases each year. The understanding of this disease has progressed considerably and its prognosis has improved because of earlier diagnosis, the introduction of appropriate strategies and the use of novel active treatments (Aapro, 2001; Sasco et al, 2003). However, as the tumour-node-metastasis (TNM) stage provides scant information on the growth pattern of each tumour, a large number of new biomarkers have been analysed to predict the risk of recurrence and to help apply the best adjuvant therapy. In this view, we paid attention to a recently identified oestrogen-regulated gene called gabarapl1 (GABA receptor-associated protein-like 1) or gec1 (glandular epithelial cell 1), which is thought to have an essential role during tumour progression (Nemos et al, 2003).

The gabarapl1 gene was originally identified as an early oestrogen-regulated gene in cultured guinea-pig endometrial glandular epithelial cells (GECs) (Pellerin et al, 1993). The human gene was then characterised (GeneBank Accession No. AF087847)

*Correspondence: Dr F Descotes, Service de Biochimie et Biologie Moléculaire Sud, Pavillon 3D, Centre Hospitalier Lyon Sud, Pierre Bénite Cedex 69495, France; E-mail: francoise.descotes@chu-lyon.fr

${ }^{6}$ These authors contributed equally to this work

Received 10 November 2009; accepted 15 January 2010; published online 2 March 2010 and its coding sequence presents $76.8 \%$ identity with that of gabarap ( $\gamma$-aminobutyric acid type A receptor-associated protein). Indeed, gabarapl1 and gabarap genes are located on 12p12.3 and 17p13.12 human chromosomes, respectively.

The GABARAPL1 protein is composed of 117 amino acids and is highly conserved throughout evolution, suggesting a critical cellular function. Similar to GABARAP, GABARAPL1 is involved in protein or vesicle intracellular transport through its interaction with cytoskeleton elements. Some publications have suggested that GABARAPL1 and GABARAP might also be involved in tumour development. Indeed, it was reported that lower levels of gabarap gene expression predict decreased survival among patients with neuroblastoma (Roberts et al, 2004). Klebig et al (2005) showed that an ectopic overexpression of the gabarap gene inhibits cancer cell proliferation and tumour growth in mice. We reported elsewhere a decrease in gabarapl1 expression in cancer cell lines (Nemos et al, 2003).

To characterise the role of gabarapl1 in breast cancer, we analysed the level of gabarapl1 expression in some breast tumour samples and the effect of its induced overexpression on the growth rate of a breast cancer cell line. We also analysed gabarapl1 mRNA expression in a retrospective cohort of 265 breast tumour biopsy samples using a reverse transcriptase-quantitative polymerase chain reaction ( $\mathrm{RT}-\mathrm{qPCR}$ ) protocol to estimate its potential prognostic effect. 


\section{MATERIALS AND METHODS}

\section{Experimental analysis}

Cell transfection Human breast cancer cells (MCF-7) were maintained as previously described (Berthier et al, 2007). The gabarapl1 coding sequence flanked by two tag sequences coding for a Flag peptide and a six-histidine tail was cloned into a pcDNA3.1 Hygro(-) vector (Invitrogen, Carlsbad, CA, USA). This construct was called pcDNA3.1-Flag-GEC1-(His) 6 . MCF-7 cells were transfected with $40 \mu \mathrm{g}$ of pcDNA3.1-Flag-GEC1-(His) ${ }_{6}$ or pcDNA3.1 control vector, and $40 \mu \mathrm{l}$ of TransFast reagent (Promega, Madison, WI, USA) according to the manufacturer's protocol. The selection of resistant cells was carried out for 20 days with $200 \mu \mathrm{g} / \mathrm{ml}$ hygromycin starting $24 \mathrm{~h}$ after transfection until single colonies could be picked.

Western blot analysis Whole-cell lysates $(40 \mu \mathrm{g})$ were loaded on a $12 \%$ SDS-PAGE and a western blot analysis was performed according to the standard protocol (Towbin et al, 1979). A monoclonal anti-Flag antibody was used at 1/6000 dilution (SigmaAldrich, St Louis, MO, USA). Signals were visualised using a goat horseradish peroxidase (HRP)-coupled anti-mouse antibody $(1 / 20000)$ (PARIS, Compiègne, France) and the ECLplus reagent (GE Healthcare Life Sciences, Pittsburgh, PA, USA) according to the manufacturer's protocol. Three independent experiments were performed for each cell lysate.

Cell proliferation assay MCF-7-Flag-GEC1-(His) 6 (clones 1 and 2) and MCF-7-pcDNA cell lines were plated in 96-well plates $(3000$ cells per well) and cell proliferation experiments were conducted over a 10-day period using 3-(4,5-dimethylthiazol-2-yl)-2,5diphenyl tetrazolium bromide (MTT) (Sigma-Aldrich) (Morel et al, 2007). For each clone, two independent experiments were performed in 16 wells. Data are means \pm s.d. and differences between clones were assessed using the Wilcoxon test ( $\mathrm{R}$ software version 2.7.1, http://cran.r-project.org).

Macroarray experiment The macroarray experiment was performed using a cancer profiling array II membrane (Clontech, Palo Alto, CA, USA). A 319-bp gabarapl1 probe, specific for the $3^{\prime}$ mRNA untranslated region, was prepared as previously described (Nemos et al, 2003). A volume of $50 \mathrm{ng}$ of gabarapl1 probe was denaturated $\left(10 \mathrm{~min}\right.$ at $\left.95^{\circ} \mathrm{C}\right)$ and randomly labelled $\left(1 \mathrm{~h}\right.$ at $\left.25^{\circ} \mathrm{C}\right)$ with $50 \mu \mathrm{Ci}$ of $\alpha\left[{ }^{32} \mathrm{P}\right]-\mathrm{dCTP}$ (Random Primer DNA Labelling System; Invitrogen). The membrane was incubated overnight with the gabarapl1 probe according to the manufacturer's protocol, exposed for $30 \mathrm{~h}$ in a Storm 840 PhosphorImager (Molecular Dynamics, Sunnyvale, CA, USA) and signals were quantified using ImageQuant TL v2005 software (GE Healthcare Life Sciences). For macroarray normalisation, the membrane was stripped according to the manufacturer's protocol and hybridised with a control ${ }^{32} \mathrm{P}$-labelled ubiquitin probe.

\section{Clinical analysis}

Patients and tumour characteristics Patients treated in three medical centres (Centre Hospitalier Régional Annecy, Chirurgie Oncologique Centre Hospitalier Universitaire Lyon-Sud and Clinique Mutualiste Saint Etienne, France) were included between October 1994 and October $2001(n=265$; Table 1). Patients were selected according to the following criteria: primary breast tumour without inflammatory features, no previous treatment and no evidence of distant metastasis at the time of diagnosis (Descotes et al, 2008). The median age at primary surgery was 53 years (range 29-89). The tumour type was determined according to the UICC-WHO criteria (Sobin and Wittekind, 1997) and histological
Table I Characteristics of the studied population

\begin{tabular}{|c|c|c|c|c|c|c|}
\hline \multirow[b]{3}{*}{ Characteristics } & \multirow{2}{*}{\multicolumn{2}{|c|}{$\begin{array}{c}\begin{array}{c}\text { All } \\
\text { patients }\end{array} \\
N=265\end{array}$}} & \multirow{2}{*}{\multicolumn{2}{|c|}{$\begin{array}{c}\begin{array}{c}\text { pNo } \\
\text { patients }\end{array} \\
N=126\end{array}$}} & \multirow{2}{*}{\multicolumn{2}{|c|}{$\begin{array}{c}\begin{array}{c}\mathrm{pN}+ \\
\text { patients }\end{array} \\
\mathbf{N}=139\end{array}$}} \\
\hline & & & & & & \\
\hline & $n$ & $\%$ & $n$ & $\%$ & $n$ & $\%$ \\
\hline \multicolumn{7}{|l|}{ Age (years) } \\
\hline$<47$ & 71 & 26.8 & 30 & 23.8 & 41 & 29.5 \\
\hline $47-53$ & 62 & 23.4 & 31 & 24.6 & 31 & 22.3 \\
\hline $53-64$ & 67 & 25.3 & 26 & 20.6 & 41 & 29.5 \\
\hline$>64$ & 65 & 24.5 & 39 & 31.0 & 26 & 18.7 \\
\hline \multicolumn{7}{|l|}{ Menopausal status } \\
\hline Pre & || | & 41.9 & 51 & 40.5 & 60 & 43.2 \\
\hline Post & 154 & 58.1 & 75 & 59.5 & 79 & 56.8 \\
\hline \multicolumn{7}{|l|}{ Surgical tumour size } \\
\hline pTI & 114 & 43.0 & 70 & 55.6 & 44 & 31.7 \\
\hline$\geqslant \mathrm{pT} 2$ & 139 & 52.5 & 52 & 41.3 & 87 & 62.6 \\
\hline ND & 12 & 4.5 & 4 & 3.2 & 8 & 5.8 \\
\hline \multicolumn{7}{|l|}{ Histological type } \\
\hline Lobular & 39 & 14.7 & 18 & 14.3 & 21 & 15.1 \\
\hline Ductal & 216 & 81.5 & 99 & 78.6 & 117 & 84.2 \\
\hline Others & 10 & 3.8 & 9 & 7.1 & I & 0.7 \\
\hline \multicolumn{7}{|l|}{ Lymph node status } \\
\hline 0 & 126 & 47.5 & 126 & 100.0 & & \\
\hline $1-3$ & 83 & 31.3 & & & 83 & 59.7 \\
\hline$>3$ & 56 & 21.1 & & & 56 & 40.3 \\
\hline \multicolumn{7}{|l|}{ SBR grade in ductal carcinoma } \\
\hline 1 & 31 & 14.4 & 17 & 17.2 & 14 & 12.0 \\
\hline 2 & 114 & 52.8 & 58 & 58.6 & 56 & 47.9 \\
\hline 3 & 57 & 26.4 & 22 & 22.2 & 35 & 29.9 \\
\hline ND & 14 & 6.5 & 2 & 2.0 & 12 & 10.3 \\
\hline \multicolumn{7}{|l|}{ ER status } \\
\hline Positive & 222 & 83.8 & 108 & 85.7 & $1 \mid 4$ & 82.0 \\
\hline Negative & 43 & 16.2 & 18 & 14.3 & 25 & 18.0 \\
\hline \multicolumn{7}{|l|}{ PgR status } \\
\hline Positive & 208 & 78.5 & 106 & 84.1 & 102 & 73.4 \\
\hline Negative & 57 & 21.5 & 20 & 15.9 & 37 & 26.6 \\
\hline \multicolumn{7}{|l|}{ Adjuvant systemic therapy } \\
\hline None & 25 & 9.4 & 25 & 19.8 & 0 & \\
\hline Hormone therapy & 90 & 34.0 & 76 & 60.3 & 14 & 10.1 \\
\hline Chemotherapy & 33 & 12.5 & 10 & 7.9 & 23 & 16.5 \\
\hline Hormone and chemotherapy & 117 & 44.2 & 15 & 11.9 & 102 & 73.4 \\
\hline
\end{tabular}

grading was scored according to the Scarff Bloom and Richardson classification (Bloom and Richardson, 1957) only in the ductal carcinomas that represented the majority $(81.5 \%)$ of cases. Oestrogen receptor (ER) and progesterone receptor (PgR) were assayed in cytosol using the radioligand reference method (EORTC, 1980). Quality control was based on regular testing of both European Organization for Research and Treatment of Cancer (EORTC) and internal controls. Results were expressed as fmol per mg cytosol protein. ER- and PgR-positive tumours contained $>2$ and $>5 \mathrm{fmol}$ per $\mathrm{mg}$ protein, respectively. All patients received locoregional radiotherapy. The majority of node-positive patients and high-risk node-negative patients (age of $<35$ years, pathological size $>20 \mathrm{~mm}$, histological grade of $\geqslant 2$ and steroid receptor-negative status) received chemotherapy. Almost all ER-positive patients were given hormone treatment. 
$R T-q P C R$ analysis Breast cancer tissue biopsy samples were obtained by surgery, selected by the pathologist and immediately stored in liquid nitrogen until processing. The biopsy samples were pulverised using a 'Mikro-Dismembrator' (B. Braun Biotech International, Melsungen, Germany) and total RNAs were extracted using TRI Reagent (Sigma). To remove any genomic DNA contamination, total RNAs were treated with RNAse-free DNAse I and purified using RNeasy microcolumns (Qiagen, Hilden, Germany). RNA quality was verified using an Agilent Bioanalyser 2100 (Agilent Technologies, Santa Clara, CA, USA). A volume of $500 \mathrm{ng}$ of total RNAs was reverse transcribed using M-MLV RT RNase $\mathrm{H}$ Minus reverse transcriptase and oligo(dT) ${ }_{15}$ primer following the manufacturer's instructions (Promega). All cDNA amplifications were performed using 1/20th of the reverse transcription products and the LC Fast Start DNA Master SYBR Green kit (Roche Applied Science, Basel, Switzerland), in the presence of $3 \mathrm{~mm} \mathrm{MgCl}_{2}$ and $0.4 \mu \mathrm{M}$ of each gabarapl1 primer. Quantitative PCR was run on a LightCycler instrument (Roche Applied Science) with the following parameters: $10 \mathrm{~min}$ at $95^{\circ} \mathrm{C}$ for the initial denaturation step, followed by $15 \mathrm{~s}$ at $95^{\circ} \mathrm{C}, 6 \mathrm{~s}$ at $60^{\circ} \mathrm{C}$ and $12 \mathrm{~s}$ at $72{ }^{\circ} \mathrm{C}$ per cycle for a total of 40 cycles. The gabarapll primers used (forward: 5'-TTTGGTGCCCCTTATCTCAC-3'; reverse: $5^{\prime}$-GGCCATCATGTAGCATTCCTT- $3^{\prime}$ ) for amplification of a 241-bp fragment (GenBank AF287012) were designed using the Primer3 software (http://fokker.wi.mit.edu/primer3/ input.htm). The amplified cDNA concentration was evaluated using an external curve of standard samples and specific amplification was checked using a melting curve. The PCR kinetics and quantitative data were determined using LightCycler software 4.05 (Roche Applied Science). The gabarapl1 target concentration was expressed relative to the concentration of the gapdh housekeeping gene. The forward primer $\left(5^{\prime}\right.$-CGACCACTTTGTCAAGCT CA- $3^{\prime}$ ) and the reverse primer (5'-AGGGGAGATTCAGTGTGGTG-3') gave an amplification product of 203 bp (GenBank NM_002046). Quality control was assessed using regular testing of two internal controls. Interassay variations were $<5 \%$ (data not shown).

Statistical analysis The median follow-up at the time of analysis was 54 months (range 2-109). The criterion for statistical analyses was metastasis-free survival (MFS), that is, the delay between the time of primary surgery and the first event: nodal or distant metastasis, or death. Neither local recurrence nor occurrence of a contralateral cancer was taken into account, nor a second primary cancer if it occurred within 2 years. Patients alive without metastasis were censored at the last follow-up date. Analysis of the distribution of gabarapll expression in relation to usual prognostic parameters was performed using the Mann-Whitney or Kruskall-Wallis test. Survival probabilities were estimated using Kaplan-Meier estimates and were compared using the logrank test. Univariate and multivariate analyses were performed using the Cox proportional hazard model. When gabarapl1 was used as a continuous variable, we used the transformed variable $\log (1 /$ gabarapl1), which therefore provided an easier interpretation of the hazard ratio (HR). Multivariate analyses were performed in a stepwise forward manner. A basal model including the clinical, pathological and biological variables (except gabarapl1) associated with prognosis was first built. The histological grade that was determined only in ductal carcinomas but not in lobular carcinomas could not be introduced in the basal model. The variables were adjusted for age. The prognostic value of gabarapl1 was tested after adding this variable to the basal model and the significance of each variable was calculated by comparing nested models using the likelihood ratio (LR) test. Trend tests were performed for ordinal variables. All tests were set at the significance level of $\alpha=0.05$. Confidence intervals (CI) referred to the $95 \%$ level. These analyses were performed with the $\mathrm{R}$ software (release 2.7.1).

\section{RESULTS}

\section{Effect of GABARAPL1 overexpression on MCF-7 growth rate}

Previous data have shown that gabarapl1 mRNA is ubiquitously expressed in human tissues (Nemos et al, 2003), but surprisingly low levels were detected in some cancer cell lines, particularly in the MCF-7 breast cancer cell line (data not shown). Therefore, we speculated whether the ectopic expression of GABARAPL1 might modify the growth rate of these cells. To find a solution, we designed a stable MCF-7 cell line overexpressing the double-tagged Flag-GEC1-(His) ${ }_{6}$ protein. Among the hygromycin-resistant colonies, 20 clones were selected and GABARAPL1 protein expression was quantified by western blotting. As shown in Figure 1A, high GABARAPL1 levels were observed in clones 1 and 2 when compared with the control cell line. To assess whether overexpression of GABARAPL1 regulated the growth rate of breast cancer cells, we performed a kinetic viability assay (MTT) using wild-type MCF-7, MCF-7-pcDNA3.1 and two MCF-7-Flag-GEC1(His) ${ }_{6}$-expressing clones. As shown in Figure 1B, GABARAPL1expressing clones 1 and 2 showed significantly reduced growth rates over 8 days of culture when compared with control cell lines.

\section{Gabarapl1 expression in normal and tumour breast tissues}

As GABARAPL1 overexpression was associated with a decreased cancer cell growth rate, it can be expected that its expression might also be altered in tumour tissues. To test this hypothesis, we analysed gabarapl1 expression in paired normal and tumour tissues using a cancer profiling array (Figure 2A). A dysregulation of gabarapll expression was found not only in breast tumours but also in several other types of tumours such as kidney, testis, bladder, pancreas and prostate (data not shown). After

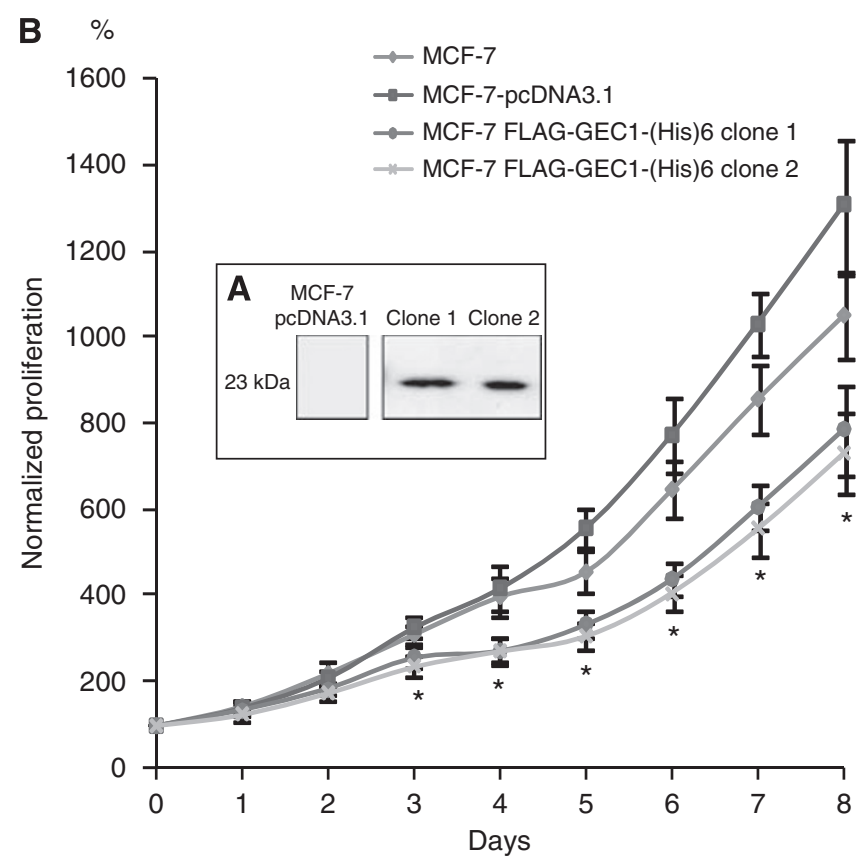

Figure I GABARAPLI overexpression negatively regulates the growth rate of MCF-7 cells. (A) Western blot analysis of MCF-7-pcDNA3.I (control) and MCF-7-Flag-GECI-(His) 6 (clones I and 2) cells using an anti-

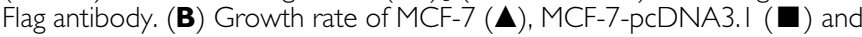
MCF-7-Flag-GECI-(His) 6 clones I (0) and 2 (*) using an MTT assay. *P $<0.05$ (Wilcoxon's test) 
A

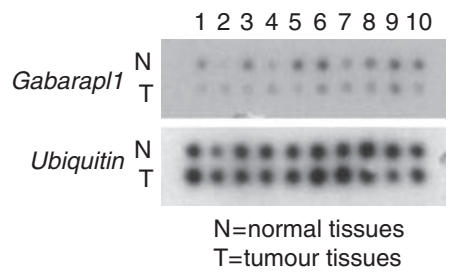

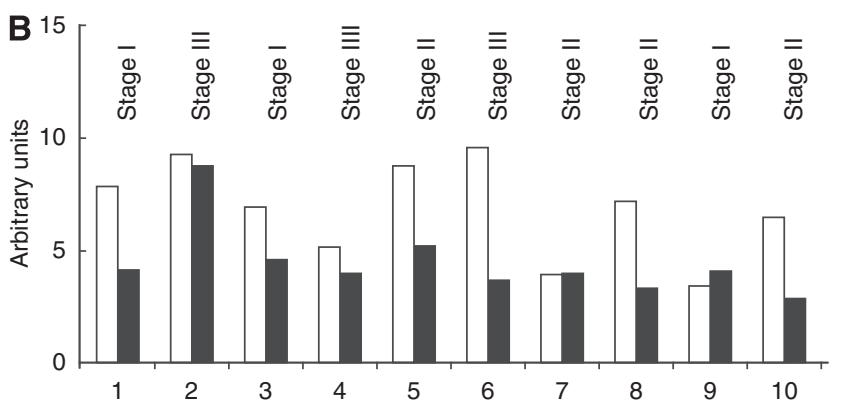

Figure 2 Macroarray hybridisation and analysis. Autoradiography of the membrane hybridised with (A) gabarap/l or ubiquitin probe. (B) Normalised gabarap// expression using the ubiquitin signal in normal (white bars) and tumoural breast tissues (black bars). The tumours at different stages correspond to infiltrating ductal carcinomas (I, 2, 4, 7, 8, 9, I0), mucinous adenocarcinoma (3), Paget's disease (5) and lobular carcinoma (6).

Table 2 gabarap/l expression in relation to the usual prognostic factors



${ }^{a}$ Histological grade defined only in ductal carcinoma. P-values correspond to Mann-Whitney test or Kruskall-Wallis test (histological grade).

normalisation with ubiquitin signal, these alterations in gabarapl1 expression in tumour breast tissues were confirmed: a downregulation was detected in 7 out of 10 breast tumours (Figure $2 \mathrm{~B}$ ).

\section{Gabarapl1 expression in 265 breast cancer cases}

To evaluate the significance of the macroarray data obtained on 10 breast tumours, we analysed gabarapl1 expression in a cohort of 265 breast tumour biopsy samples. The mean gabarapl1 value measured by RT-qPCR was 5.03 and the median was 4.54 (range $0.16-17.27)$. Table 2 shows the median value of gabarapll in relation to several tumour characteristics that are usually linked to prognosis. Indeed, in the whole population, the median gabarapl1 expression was significantly different in relation to surgical size, histological grade, lymph node, ER and PgR status. The histological type, ductal or lobular, revealed no difference. A lower gabarapl1 expression was significantly related to tumour size of $>20 \mathrm{~mm}$ only in the whole population and in the $\mathrm{pN}+$ subset.

It may be observed that the median values were significantly lower in the pejorative categories of tumours. Therefore, after testing that the gabarapl1 distribution was log normal (data not shown), for studies requiring a dichotomy of the variable, the cutoff value (6.56) was found to be equal to the upper threshold of the third quartile, allowing a discrimination between high and low gabarap1l expression status.

\section{Univariate analysis}

Results of the univariate MFS analysis (Table 3) show the relation between gabarapl1 expression levels and common prognostic factors: low levels were associated with pejorative prognostic factors. As usually observed, age and surgical tumour size were 
Table 3 Cox univariate analysis for metastasis-free survival

\begin{tabular}{|c|c|c|c|c|c|c|c|c|c|}
\hline \multirow[b]{2}{*}{ Characteristics } & \multicolumn{3}{|c|}{ All patients $(n=265)$} & \multicolumn{3}{|c|}{ pN0 patients $(n=126)$} & \multicolumn{3}{|c|}{ pN+ patients $(n=139)$} \\
\hline & HR & Cl & $P$-value & HR & $\mathbf{C l}$ & $P$-value & HR & $\mathbf{C l}$ & $P$-value \\
\hline \multicolumn{10}{|l|}{ Age (years) } \\
\hline$<48$ & 3.22 & $1.50-6.93$ & & 6.29 & $0.73-54.16$ & & 2.42 & $1.06-5.54$ & \\
\hline $48-53$ & 1.30 & $0.55-3.09$ & & 2.18 & $0.20-24.09$ & & 1.06 & $0.42-2.69$ & \\
\hline $54-64$ & 0.67 & $0.26-1.69$ & & 1.76 & $0.16-19.64$ & & 0.42 & $0.15-1.15$ & \\
\hline$>64$ & 1.00 & & $<0.001$ & 1.00 & & 0.202 & 1.00 & & $<0.001$ \\
\hline \multicolumn{10}{|l|}{ Menopausal status } \\
\hline Pre & 1.65 & $0.97-2.82$ & & 3.60 & $0.93-13.97$ & & 1.40 & $0.77-2.52$ & \\
\hline Post & 1.00 & & 0.066 & 1.00 & & 0.064 & 1.00 & & 0.271 \\
\hline \multicolumn{10}{|l|}{ Surgical tumour size } \\
\hline pTI & 1.00 & & & 1.00 & & & 1.00 & & \\
\hline$\geqslant \mathrm{pT} 2$ & 3.64 & $1.83-7.25$ & 0.001 & 1.80 & $0.50-6.44$ & 0.365 & 3.57 & $1.50-8.45$ & 0.004 \\
\hline \multicolumn{10}{|l|}{ Lymph node status } \\
\hline pNO & 1.00 & & & & & & & & \\
\hline $\mathrm{pN}+$ & 3.67 & $1.85-7.30$ & $<0.00$ I & & & & & & \\
\hline \multicolumn{10}{|l|}{ Histological grade ${ }^{a}$} \\
\hline I & 1.00 & & & 1.00 & & & & & \\
\hline 2 & 6.06 & $0.82-44.93$ & & 0.80 & $0.09-7.21$ & & & & \\
\hline 3 & 10.90 & $1.46-81.46$ & 0.004 & 1.71 & $0.19-15.44$ & 0.494 & & & $N A^{b}$ \\
\hline \multicolumn{10}{|l|}{$E R$ and $P g R$ status } \\
\hline ER and PgR positive & 1.00 & & 0.001 & 1.00 & & 0.261 & 1.00 & & $<0.001$ \\
\hline ER and/or PgR negative & 2.47 & $1.44-4.23$ & & 0.31 & $0.04-2.42$ & & 3.43 & $1.89-6.23$ & \\
\hline \multicolumn{10}{|l|}{ Gabarap// status } \\
\hline
\end{tabular}

Abbreviations: $\mathrm{HR}=$ hazard ratio; $\mathrm{Cl}=$ confidence interval; $\mathrm{ER}=$ oestrogen receptor; PgR = progesterone receptor. $\mathrm{P}$-values correspond to Cox regression model. a Histological grade defined only in ductal carcinoma. ' $\mathrm{No}$ events in histological grade I tumour subset. 'HR for an increase of one log (I/gabarap/I).

significant prognostic factors in the whole population and in the $\mathrm{pN}+$ subset, but not in pN0 patients. In the whole population, lymph-node status was correlated with risk of metastasis (HR 3.67, $P<0.001)$. It was also observed that the risk of metastasis in relation to low gabarapl1 levels increased by 4.96 -fold in the whole population (CI $2.43-10.12 ; P<0.001$ ) and by 14.96 -fold in the $\mathrm{pN}+$ subset $(\mathrm{CI} 4.80-46.60 ; P<0.001)$. In $\mathrm{pN} 0$ patients, gabarapl expression was not related to risk of metastasis.

Kaplan-Meier curves were constructed after segmentation into two groups on the basis of the gabarapl1 expression cutoff (Figure 3). It was observed that high values of gabarapl1 expression were related to a good prognosis. They were predictive of longer MFS in all patients (Figure $3 \mathrm{~A}, P<0.001$ ) and in $\mathrm{pN}+$ patients (Figure $3 \mathrm{~B}, P<0.001$ ) but not in $\mathrm{pN} 0$ patients (data not shown). It is noteworthy that, in the high gabarapll $\mathrm{pN}+$ subgroup, only one patient relapsed.

\section{Multivariate analysis}

In the whole population, the multivariate analysis applied to the basal model (Table 4) showed, as expected, a significantly higher risk of metastasis associated with surgical tumour size of $>20 \mathrm{~mm}$ (HR 3.00; $P=0.002$ ), lymph node-positive status (HR 2.93; $P=0.002$ ) and $\mathrm{ER}$ and/or PgR-negative status (HR 2.15; $P=0.007)$.

In $\mathrm{pN}+$ patients, surgical tumour size of $>20 \mathrm{~mm}$ (HR 3.59; $P=0.004)$ and ER- and/or PgR-negative status (HR 2.92; $P=0.001)$ were significantly related to higher metastasis risk, whereas none of these factors were related to the risk of metastasis in pN0 patients. When gabarapll expression was included in this basal model, low gabarapll values were associated with an increased metastasis risk by 3.63 -fold in the whole population (CI $1.48-8.93, P=0.005$ ) and by 5.65 -fold in the $\mathrm{pN}+$ subset (CI 1.84-17.29, $P=0.002$ ). It is observed that in pN0 patients, the risk of metastasis was not significantly related to gabarapl1 expression levels.

\section{DISCUSSION}

In this study, we provide for the first time an insight into the effect of GABARAPL1 overexpression in breast cancer cells and into the effect of gabarapl1 expression level in a large retrospective cohort of breast tumours.

We have reported that GABARAPL1 is able to bind to tubulin and could be involved in the transport of the $\mathrm{GABA}_{\mathrm{A}}$ receptor (Mansuy et al, 2004). It also has an important role in the transport of other receptors such as the $\kappa$-opioïd receptor (Chen et al, 2006). Nevertheless, gabarapl $1 \mathrm{mRNA}$ is widely distributed in human tissues (Nemos et al, 2003), suggesting that GABARAPL1 protein is not only involved in the transport of receptors but probably has a more complex role in cells. Particularly, it could be involved in cell cycle regulation, as it interacts with tubulin (Mansuy et al, 2004). Our study showed that MCF-7 cells overexpressing GABARAPL1 


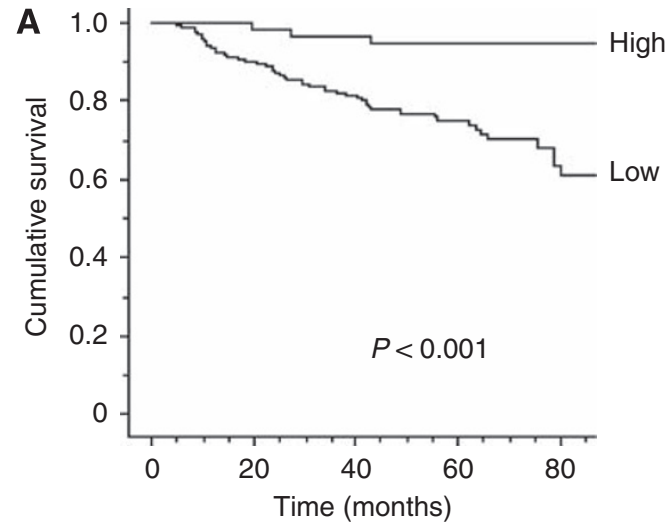

Number of events

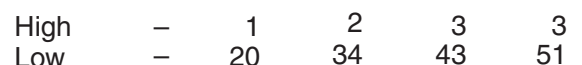

Number at risk

$\begin{array}{lrrrrr}\text { High } & 68 & 64 & 51 & 30 & 22 \\ \text { Low } & 197 & 166 & 131 & 78 & 26\end{array}$

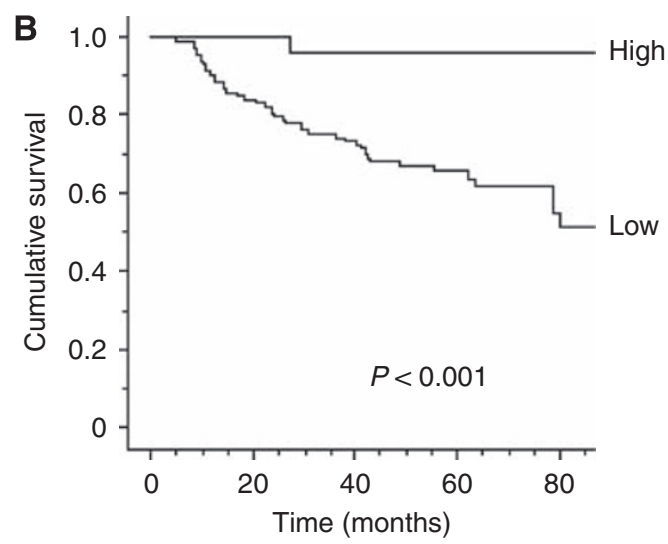

Number of events

\begin{tabular}{|c|c|c|c|c|}
\hline High & - & 0 & 1 & 1 \\
\hline Low & - & 19 & 31 & 38 \\
\hline
\end{tabular}

Number at risk

$\begin{array}{lrllll}\text { High } & 25 & 24 & 23 & 18 & 15 \\ \text { Low } & 114 & 93 & 81 & 41 & 15\end{array}$

Figure 3 Kaplan-Meier curves for metastasis-free survival probabilities according to gabarap/l expression categorised with quartiles from $(\mathbf{A})$ the whole population $(n=265)$ and $(\mathbf{B}) \mathrm{pN}+$ patients $(n=139)$. Low: $\leqslant 75 \%$ quartile; high: $>75 \%$ quartile.

protein had a significantly decreased growth rate, compared with control cell lines. This finding was in favour of a potential role of GABARAPL1 in the control of cell proliferation as previously reported for GABARAP overexpression in CAL51 cells (Klebig et al, 2005). These data suggested that gabarapll expression could be altered in rapidly growing breast tumour tissues. In fact, in the macroarray experiment, most breast tumour tissues presented weaker gabarapl mRNA levels than did normal tissues. These results concorded with previous findings in breast cancer cell lines, in which very low levels of gabarapl1 mRNAs were observed (data not shown). Experiments are needed to determine whether somatic mutations (Tomlinson, 2001) or epigenetic events (Lo and Sukumar, 2008) are responsible for the gabarapl1 downregulation in these cell lines.
Gabarapl1 expression has been analysed in this study for the first time in a retrospective cohort of 265 breast tumours. The data obtained during this investigation showed that gabarapl1 expression is significantly different in relation to usual prognostic criteria such as tumour size, lymph-node and steroid receptor status. It is also shown that gabarapl1 expression median values are different in relation to tumour oestrogen and progesterone receptor status: the median is higher in ER- and PgR-positive tumours, in agreement with Mansuy et al (2004) who showed that gabarapl1 is an oestrogen-regulated gene.

Furthermore, we showed that tumours expressing low levels of gabarapl1 were observed to be significantly associated with high risk of metastasis in the $\mathrm{pN}+$ subset $(\mathrm{HR}=14.96, P<0.001)$ but not in pN0 patients (Table 3). In the whole population, KaplanMeier curves (Figure 3A) showed that after 80 months of followup, only 3 out of 25 patients showing high gabarapl1 levels presented a recurrence compared with 51 out of 77 patients with low gabarapl1 levels. In the $\mathrm{pN}+$ subset (Figure 3B), 1 out of 16 patients with a high gabarapl1 level relapsed, compared with 43 out of 58 with a low gabarapl1 level. These data clearly show that the gabarapl1 expression level is negatively correlated with the risk of metastasis.

In this study, the difference in gabarapl1 expression between ductal and lobular types, which show different growth patterns, is not significant. It can be observed that the median gabarapl1 level is higher in lobular tumours, which are known to be less aggressive than ductal ones (Table 2). The difference in gabarapll expression between both types is not significant, but it can be observed that the number of lobular tumours is very small. Moreover, we found a significant correlation between gabarapl1 expression and the other pathological features related to prognosis, such as tumour size, histological grade, lymph node and ER and PgR status.

Previous results using RT-qPCR analysis on 235 neuroblastomas showed that lower GABARAP expression levels were associated with more advanced stages (Roberts et al, 2004). Moreover, tissue microarray experiments revealed a significant reduction in GABARAP protein expression in a high proportion of 93 breast cancers cases (Klebig et al, 2005). However, no correlation was observed between loss of GABARAP expression and clinicopathological features such as grading, tumour size, oestrogen receptor status and age of diagnosis. In the latter publication, the researchers used a polyclonal anti-GABARAP antibody (Alpha Diagnostics, San Antonio, TX, USA) to perform immunostaining of tissue microarrays. However, we have reason to believe that no commercially available antibody is able to clearly distinguish between GABARAP and GABARAPL1 proteins because of their high degree of identity. Indeed, all the polyclonal commercial and homemade antibodies we have tested so far in the laboratory recognised both GABARAPL1 and GABARAP proteins (Mansuy et al, 2004; Tolle et al, 2008). Therefore, immunostaining analysis is unreliable and, up to now, the unique alternative to differentiate gabarapl1 and gabarap expression is the use of specific RT-qPCR primers located in $3^{\prime}$-untranslated regions.

It can be considered that despite their high homology, gabarapl1 and gabarap are probably differently regulated during the course of breast cancer progression. Nevertheless, it would be of great interest to further study the expression levels of these two closely related genes to determine whether these present the same pattern of expression in breast cancers.

\section{CONCLUSIONS}

Our data strongly suggest that, in breast cancers, high levels of gabarapl1 mRNA are correlated with a low risk of metastasis. This is valid in the whole population, but specifically in lymph 
Table 4 Cox multivariate analysis of metastasis-free survival

\begin{tabular}{|c|c|c|c|c|c|c|c|c|c|}
\hline \multirow[b]{2}{*}{ Characteristics } & \multicolumn{3}{|c|}{ All patients $(n=253)$} & \multicolumn{3}{|c|}{ pN0 patients $(n=122)$} & \multicolumn{3}{|c|}{ pN+ patients $(n=131)$} \\
\hline & HR & $\mathbf{C l}$ & $P$-value & HR & $\mathbf{C l}$ & $P$-value & HR & $\mathbf{C l}$ & $P$-value \\
\hline \multicolumn{10}{|l|}{ Surgical tumour size } \\
\hline pTI & 1.00 & & & 1.00 & & & 1.00 & & \\
\hline$\geqslant \mathrm{pT} 2$ & 3.00 & $1.49-6.00$ & 0.002 & 1.81 & $0.51-6.48$ & 0.360 & 3.59 & $1.51-8.54$ & 0.004 \\
\hline \multicolumn{10}{|l|}{ Lymph node status } \\
\hline \multicolumn{10}{|l|}{$E R$ and $P g R$ status } \\
\hline ER and PgR positive & 1.00 & & & 1.00 & & & 1.00 & & \\
\hline ER and/or PgR negative & 2.15 & $1.24-3.75$ & 0.007 & 0.35 & $0.04-2.80$ & 0.325 & 2.92 & $1.56-5.46$ & 0.001 \\
\hline \multicolumn{10}{|l|}{ Basal model and gabarapll } \\
\hline \multicolumn{10}{|l|}{ Surgical tumour size } \\
\hline PTI & 1.00 & & & 1.00 & & & 1.00 & & \\
\hline \multicolumn{10}{|l|}{ Lymph node status } \\
\hline ER and PgR positive & 1.00 & & & 1.00 & & & 1.00 & & \\
\hline ER and/or PgR negative & 1.73 & $0.96-3.12$ & 0.007 & 0.21 & $0.02-2.27$ & 0.200 & 2.41 & $1.26-4.62$ & 0.008 \\
\hline \multicolumn{10}{|l|}{ Gabarap/I status } \\
\hline Log $\left(\right.$ I/gabarap/I) ${ }^{a}$ & 3.63 & $1.48-8.93$ & 0.005 & 3.79 & $0.32-45.64$ & 0.294 & 5.65 & $1.84-17.29$ & 0.002 \\
\hline
\end{tabular}

Abbreviations: $\mathrm{HR}=$ hazard ratio; $\mathrm{Cl}=$ confidence interval; $\mathrm{ER}=$ oestrogen receptor; $\mathrm{PgR}=$ progesterone receptor. All values were adjusted by age. ${ }^{\mathrm{a}} \mathrm{HR}$ for an increase of one log /gabarap/I). P-values correspond to Cox regression model.

node-positive patients (HR 5.65; $P=0.002$ ). The gabarapl1 gene might show an important effect on tumour progression. To our knowledge, all publications currently available only describe the role of GABARAPL1 protein during the intracellular transport of receptors in the brain. Hence, this investigation is the first one describing a new interesting function of this gene in breast tissues. These data open up a new point of view on the importance of this small protein called GABARAPL1 in different pathways and tissues and offer a great potential for this gene as a novel prognostic indicator for patients developing breast cancer.

\section{REFERENCES}

Aapro MS (2001) Adjuvant therapy of primary breast cancer: a review of key findings from the 7th International Conference, St Gallen, February 2001. Oncologist 6: $376-385$

Berthier A, Girard C, Grandvuillemin A, Muyard F, Skaltsounis AL, Jouvenot M, Delage-Mourroux R (2007) Effect of 7-O-beta-D-glucopyranosylchrysin and its aglycone chrysin isolated from Podocytisus caramanicus on estrogen receptor alpha transcriptional activity. Planta Med 73: 1447-1451

Bloom HJ, Richardson WW (1957) Histological grading and prognosis in breast cancer; a study of 1409 cases of which 359 have been followed for 15 years. Br J Cancer 11: 359-377

Chen C, Li JG, Chen Y, Huang P, Wang Y, Liu-Chen LY (2006) GEC1 interacts with the kappa opioid receptor and enhances expression of the receptor. J Biol Chem 281: 7983-7993

Descotes F, Riche B, Saez S, De Laroche G, Datchary J, Roy P, André J, Bobin JY (2008) Plasminogen activator inhibitor type 1 is the most significant of the usual tissue prognostic factors in node-negative breast ductal adenocarcinoma independent of urokinase-type plasminogen activator. Clin Breast Cancer 8: $168-177$

EORTC (1980) Revision of the standards for the assessment of hormone receptors in human breast cancer; report of the second E.O.R.T.C. Workshop, held on 16-17 March, 1979, in the Netherlands Cancer Institute. Eur J Cancer 16: 1513 - 1515

\section{ACKNOWLEDGEMENTS}

This research work was supported by the Ministère de l'Enseignement Supérieur et de la Recherche, by the Région Franche-Comté and by the Ligue Nationale Contre le Cancer (Drôme, HauteSavoie, Jura, Loire, Saône and Loire and Rhône committees). We are grateful to the clinical teams from Annecy (Vincent B, Chenet P, Knopf JF, Poulleau S, Cocchi P), Lyon (Berger F, Isaac S) and St Etienne (Bouteille C, Griot A, Griot JP, Malvolti B, Villard P). We also thank John Carew for editorial help.

Klebig C, Seitz S, Arnold W, Deutschmann N, Pacyna-Gengelbach M, Scherneck S, Petersen I (2005) Characterization of \\{gammal\}-aminobutyric acid type A receptor-associated protein, a novel tumor suppressor, showing reduced expression in breast cancer. Cancer Res 65: 394-400

Lo PK, Sukumar S (2008) Epigenomics and breast cancer. Pharmacogenomics 9: $1879-1902$

Mansuy V, Boireau W, Fraichard A, Schlick JL, Jouvenot M, DelageMourroux R (2004) GEC1, a protein related to GABARAP, interacts with tubulin and GABA(A) receptor. Biochem Biophys Res Commun 325: $639-648$

Morel C, Adami P, Musard JF, Duval D, Radom J, Jouvenot M (2007) Involvement of sulfhydryl oxidase QSOX1 in the protection of cells against oxidative stress-induced apoptosis. Exp Cell Res 313: 3971-3982

Nemos C, Mansuy V, Vernier-Magnin S, Fraichard A, Jouvenot M, DelageMourroux R (2003) Expression of gec1/GABARAPL1 vs GABARAP mRNAs in human: predominance of gec1/GABARAPL1 in the central nervous system. Brain Res Mol Brain Res 119: 216-219

Pellerin I, Vuillermoz C, Jouvenot M, Ordener C, Royez M, Adessi GL (1993) Identification and characterization of an early estrogen-regulated RNA in cultured guinea-pig endometrial cells. Mol Cell Endocrinol 90: R17-R21

Roberts SS, Mori M, Pattee P, Lapidus J, Mathews R, O’Malley JP, Hsieh YC, Turner MA, Wang Z, Tian Q, Rodland MJ, Reynolds CP, Seeger RC, 
Nagalla SR (2004) GABAergic system gene expression predicts clinical outcome in patients with neuroblastoma. J Clin Oncol 22: 4127-4134

Sasco AJ, Kaaks R, Little RE (2003) Breast cancer: occurrence, risk factors and hormone metabolism. Expert Rev Anticancer Ther 3: $546-562$

Sobin LH, Wittekind C (eds) (1997) Breast tumours (ICD-O C50). In TNM Classification of Malignant Tumours, 5 edn, pp 123-130. Wiley-Liss: New York
Tolle F, Risold PY, Mansuy-Schlick V, Rossi E, Boyer-Guittaut M, Fraichard A, Jouvenot M (2008) Specific regional distribution of gec1 mRNAs in adult rat central nervous system. Brain Res 1210: $103-115$

Tomlinson IP (2001) Mutations in normal breast tissue and breast tumours. Breast Cancer Res 3: 299-303

Towbin H, Staehelin T, Gordon J (1979) Electrophoretic transfer of proteins from polyacrylamide gels to nitrocellulose sheets: procedure and some applications. Proc Natl Acad Sci USA 76: 4350-4354 